\title{
Low Carbon Exploration in Urban Revitalization in Yangzhou Old City Project
}

\author{
Longbin $\mathrm{Zhu}^{1 *}$, Hongyan Xiang ${ }^{1}$, Qiaoli Zhang ${ }^{1}$ \\ ${ }^{1}$ Nanjing Tech University, Nanjing 211816, China
}

\begin{abstract}
Low-carbon and ecological city and sustainable conservation of historic urban areas are issues that need to be addressed in current urban development in China. Based on the principles of community participation, local adaptive technology and cost-benefit balance, Nanhexia Low-carbon Community Project in Yangzhou proposed holistic strategies and solutions to achieve low-carbon community by means of lowcarbon planning, low-carbon transportation, energy efficiency of building, low-carbon behavior, and greening in open space. The project innovatively integrated low carbon concepts into regeneration of old city, combined traditional architectural styles with modern green technologies, and won the first platinum award of LEED Homes in China. The experience of the project may provide reference for the regeneration of other communities or other similar projects in old cities.
\end{abstract}

\section{Introduction}

Research and practice concerning low-carbon communities and cities cover areas as policies, planning \& design, construction and operation at the city, community, and building levels under the goals of sustainable, green, and ecological development, energy conservation, etc. Studies have been made on low-carbon concepts and technical measures, including planning goals and principles, land use and spatial layout, energy, transportation, water system, green landscape, public services and infrastructure, as well as on planning tools and practice cases [1-3]. These studies overlap but with different focuses, forming a comprehensive framework [4].

Some studies regard low-carbon goal as a key part of the framework of sustainable and ecological goals, proposing planning and design principles based on lowcarbon concepts, and exploring how to systematically apply these principles in the planning, construction and operation of communities [5-7]. More researches are distributed in different professional fields, focusing on low-carbon strategies in a certain field, such as intensive and mixed land use, spatial layout to reduce building energy requirements [8], and low-carbon or carbon-free approaches through technological innovation and renewable energy utilization [9], and carbon emission reduction by encouraging participation and cooperating with community residents to change their daily behaviors [10]. In the context of urban transformation and urban renewal, relevant research also extends to existing communities, discussing low-carbon goals, planning and design strategies and technical methods that should not be ignored in community regeneration [11].

Meanwhile, low-carbon concept, or as part of the green and ecological concept, appears in a large number of practices, such as Bedd-Zed, Freiburg-Vauban, the Dockside Green Community, and the ECO-LIFE EU demonstration project. In recent years, low-carbon concept, low-carbon targets and low-carbon measures have been gradually introduced into many ecological urban development projects in China, such as Changxindian Low-carbon District.[12] However, there are still few explorations and practices in the regeneration of urban communities, especially in the renewal of historical districts.

The Nanhexia pilot project is in the old city of Yangzhou, on an abandoned factory plot, covering an area of about $4000 \mathrm{~m}^{2}$. This abandoned factory was built in the 1970s. The building quality is poor, and the architectural style is inconsistent with the style of the old city. The community where the project lies covers an area of about 7.6 ha. It is dominated with buildings of traditional courtyard-style 1 to 2 -storey houses, in which old streets and lanes with a width of $1-2 \mathrm{~m}$ crisscross. (See figure 1) The internal traffic connections are mainly by walking, bicycles, and electrical bicycles. Most of the existing buildings in the community are residential. The problems of the community include insufficient public service facilities, lack of open spaces, etc. The city government hopes to explore a new approach, trying to integrate low-carbon construction with community regeneration in the old city, as a part of sustainable conservation.

\section{Concept and approach}

longbinzhu@hotmail.com 
The starting point of the Nanhexia Community Pilot Project is that the renewal of the plot in such historical district is not simply a restoration and redevelopment, but a part of the rejuvenation of the entire community. So, the residents' understanding and participation in the development plan is indispensable. With international cooperation background, the project team draws on the experiences and ideas of low-carbon community at home and abroad, and puts forward concepts and approaches of the project based on extensive exchanges with the local government, community leaders and residents:

- Integrate low-carbon community concepts into the old city regeneration;

- Improve the residents' living quality and revitalize the old city without increasing the carbon emission in the old city;

- Explore holistic low-carbon community strategies. Learning from international experiences, find out adaptable and replicable techniques in the whole process of planning, design, construction, operation and management;

- Explore the optimal integration of local traditions and low-carbon measures, and experiment with low-carbon energy-saving measures for new buildings and house renovation;

- Ensure community participation in planning and implementation.

\section{Planning and design based on community participation}

The upgraded plot is weaved into the surrounding community with its functions and spatial forms that were determined based on the comprehensive discussion at the community workshops during the planning and design process.

The functions of the buildings in the plot are improved to meet the residents' needs for public service. Neighborhood center, public activity venues and small commercial restaurants to serve residents are set up. Meanwhile, low-carbon displays and youth hostels, etc., are also set up to promote low-carbon theme and improve the attractiveness and economic vitality of the community.

In terms of spatial form, according to the texture and street-lane system of the old city, a basic frame for the road and building layout is formed, and the pedestrianprioritized road network is repaired and improved. The residents and local experts agreed on keeping Yangzhou's traditional architectural style in appearance, but adopting new indoor approaches to meet the needs of modern people. Therefore, the newly built part is well integrated into the historical environment with its traditional courtyard layout, slope roof form and lane texture; the internal function, structure, and building materials better serve the needs of residents. (See figure 2) Meanwhile, low-carbon and energy-saving measures are well integrated, such as the optimized building shape and orientation, isolation, solar energy use measures, etc. (See figure 3).

In order to hear the needs and opinions of the community and residents, in the early planning stage, the project team discussed the functional configuration and spatial layout of the plot with the local community and residents for multiple rounds (see figure 4). With the help of the 3D-Simulation and VR, the planning team established a smooth channel to communicate with the residents.

\begin{tabular}{|c|c|}
\hline $\begin{array}{l}\text { Figure 1. Plan of pilot community, abandoned factory plot } \\
\text { in the middle. }\end{array}$ & $\begin{array}{c}\text { Figure 2. New buildings integrated into historical } \\
\text { environment }\end{array}$ \\
\hline & 201 \\
\hline Figure 3. A typical energy-efficient courtyard building & $\begin{array}{l}\text { Figure 4. Planning workshop with community } \\
\text { participation }\end{array}$ \\
\hline
\end{tabular}




\section{Integrated low-carbon community strategy}

In order to achieve the goal of the project being innovative, demonstrative and extensively reproducible, an integrated strategy of low-carbon community was proposed based on the principles of adaptable technology, cost-benefit balance and community participation, which includes low-carbon planning, green buildings, low-carbon transportation and travel, low-carbon behavior, and greening in open space (see figure.5). All relevant stakeholders jointly determined on the development goals of low-carbon community and selected appropriate carbon reduction measures.

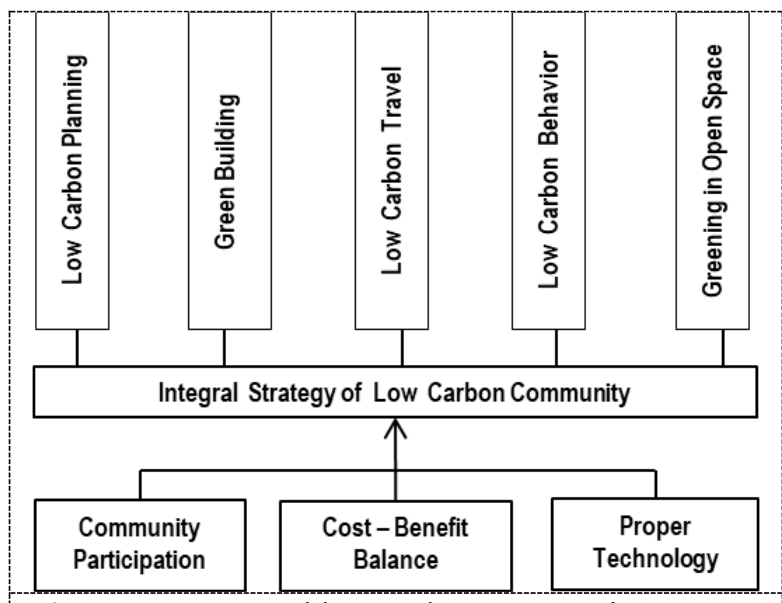

Figure 5. Integrated low-carbon community strategy

\subsection{Low-carbon planning}

The planning team optimized planning and design schemes for the low-carbon and ecological goals of the project, with reasonable functional layout, comprehensive public services, green space and public activity space for reducing transportation demand. Based on energy saving concept, the planning scheme is optimized in terms of shape, layout, building sunshine, and wind environment to reduce the energy consumption for the air conditioning of the buildings.

\subsection{Low-carbon transportation and travel}

The project restores the traditional texture, opens up the dead-ended streets and lanes in the community, and forms a complete and continuous pedestrian network. There is no car traffic in the pilot area, and the main travel modes are walking and bicycle, which is in accord with the existing street and lane system. Travel is reduced by means of mixed functions. Most of the traffic behaviors closely related to daily life is controlled within the reach of walking and bicycles, and a convenient transfer system with bus stops surrounding the plot ensures the residents' accessibility to public transport for medium and long distance travel.

\subsection{Green building and energy saving}

The project team considered energy-saving measures both for the new buildings and the old residential buildings in the community. With reference to the "Design Standards for Energy Efficient Residential Buildings in Hot Summer and Cold Winter Areas" and
" Green Building Evaluation System", with comprehensive consideration of the local energy consumption habits and relevant standards in Yangzhou, the project team developed appropriate targets and adaptable technical solutions based on energy consumption simulation and cost-benefit analysis of different combinations with different options. The key measures include: (1) Combine the traditional building form with energy efficiency requirement; (2) Prioritize passive energy efficiency measures in the design: optimize the shape and layout of the building through the simulation of sunlight, shadow and wind environment, to ensure better conditions for passive and active solar energy use, realize good natural ventilation and reduce the demand for air conditioning in summer; (3) Improve the efficiency of heating and air-conditioning equipment; (4) Use renewable energy; (5) Apply new wood structure building system and integrate it into traditional residential forms; (6) Reuse the materials from the demolished buildings.

\subsection{Low-carbon behavior}

Community participation and low-carbon behavior are important components of low-carbon strategy, which is also a major feature of the project. Yangzhou had introduced the approach of "community action plan" in the upgrading of residential houses, and successfully carried out its pioneering experiments in the participation-oriented renewal of the old city. [13] This project continued to apply the community participation method. Residents participated in the discussion of community development vision and design, and jointly formulated community low-carbon action plans to enhance residents' awareness. Based on the local conditions of the community, the project team compiled 
a guideline for low-carbon house renovation to guide residents' spontaneous renovation activities. A residents' low-carbon behavior manual was also made to guide residents' behaviors in terms of electricity, water, oil, gas, and green travel.

\subsection{Greening and open space}

The Yangzhou old city is densely packed with houses, lacking greening and public open space. Thus, the community residents' views were taken, and small squares were added to the plot in addition to neighborhood center and relevant facilities. Meanwhile, in conjunction with low-carbon actions, the community's open space was gradually upgraded, with street greening, courtyard greening, vertical greening and roof greening being added in a seamless manner, which not only improves the quality of external space, but also achieves the goal of carbon reduction. Approximately $800 \mathrm{~m}^{2}$ of greenery is added in the pilot plot, and additional 1,200 $\mathrm{m}^{2}$ greenery is achieved by means of the upgrading of the surrounding community. By planting trees, shrubs and vertical greening, the green value of the community will increase to about $2400 \mathrm{~m}^{3}$.

\section{Construction implementation and carbon reduction effect calculation}

\subsection{Introduce LEED certification}

Before the construction implementation, in order to improve the low carbon and innovation level, and the demonstration effect of the pilot project, the project team fully studied the Green Building Evaluation System of China, LEED-ND and the LEED Homes series. Based on the project conditions, the team decided to take the Platinum Award of the LEED Homes series as the standard for design and construction, optimizing the design scheme, and improving the energy-saving solutions with reference to the energy consumption and innovative indicators of the LEED Homes certification system. Strict environmental protection standards were followed during the construction work, and strict technical acceptance tests were carried out after the completion of the construction, such as air tightness testing.

The implementation process of the project became also a process of cultivating the residents' low-carbon awareness. The finished pilot project has restored the traditional style and texture, and added vitality to the community. It has provided the residents with more public space for communication and activities. The project has also become a demonstration of energysaving renovation of old city buildings and low-carbon community construction (see figure 6).

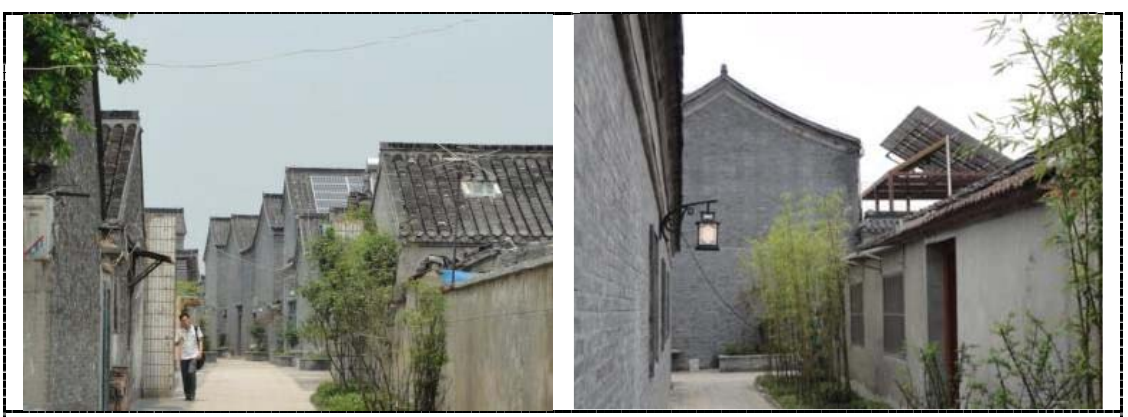

Figure 6. Buildings, lanes and courtyards after construction

\subsection{Carbon reduction effect calculation}

There is currently not unified method and standard for the calculation of the carbon reduction effect of existing communities. The project team refers to relevant international and domestic measurement methods, used rapid assessment tool online, and determined the residents' carbon emission baseline after conducting indepth investigations on the household energy, water, transportation, etc. of the residents. On this basis, the carbon reduction effect of the project has been measured. In terms of the carbon emission reduction from travel, if the average annual fuel consumption of a car is $1440 \mathrm{~L}$, if the gasoline emission is $0.785 \mathrm{~kg} \mathrm{CO}_{2}$ per liter, and if the private car ownership is one every 4 households, then the total annual $\mathrm{CO}_{2}$ emission reduction in the car-free community with a full pedestrian and bicycle transportation system will reach $233280 \mathrm{~kg}$; In terms of the energy saving in the buildings, the new construction is about $3000 \mathrm{~m}^{2}$ in the upgraded plot, if $65 \%$ of the
$120 \mathrm{kwh} / \mathrm{a} \mathrm{m}^{2}$ can be saved as a standard, then the energy saving potential will be $234000 \mathrm{Kwh} / \mathrm{a}$, which is equal to about an annual $\mathrm{CO}_{2}$ emission reduction of $233298 \mathrm{~kg}$. In terms of the carbon neutral effect of greening, if $1 \mathrm{~m}^{3}$ greening can neutralize $11.83 \mathrm{~kg} \mathrm{CO}_{2}$ emissions annually, then the annual $\mathrm{CO}_{2}$ emission reduction of $2400 \mathrm{~m}^{3}$ greening will reach $52,000 \mathrm{~kg}$. In other words, the approaches taken in travel modes, energy saving of buildings and greening alone will bring about an annual carbon emission reduction of about 520 tons. Since reproducibility had been emphasized for easy promotion in similar renewal projects in the old city of Yangzhou, the experimental approaches in this pilot project pose great potentials for carbon reduction.

\section{Conclusion}

In the context of the urban sprawl and the large-scale development projects under the name of "low-carbon eco-city" in some cities, the Nanhexia pilot project 
introduced concepts and approaches of low-carbon community in the old city regeneration of Yangzhou, and experimented with new regeneration models based on community participation. With participatory planning, careful design and construction process and strict technical acceptance testing, the Nanhexia low-carbon community project has been the first project in China that has won the LEED Homes Platinum Award, and it has received wide recognition and influence. The planning and construction implementation process turns into a process for extensive participation, learning and promotion. The integrated strategy for low-carbon community construction based on the principles of adaptable technologies, cost- benefit balance, and community participation is highly replicable. The experience of the project may provide reference for the regeneration of other communities or other similar projects in old cities.

\section{References}

1. Bott H., Grassi G., Anders S. (2013) Nachhaltige Stadtplanung: Konzepte für nachhaltige Quartiere. Edition Detail, Muenchen.

2. Pollalis S. N. (2016) Planning Sustainable Cities: An infrastructure-based approach. Routledge, Abingdon.

3. China Urban Science Research Association. (2019) China Low-Carbon Eco-City Development Report. China Construction Industry Press, Beijing.

4. Shi L., Xu T., Gao L., Han L., Li Q. (2018) Urban low-carbon communities under a sustainable framework. J. Acta Ecologica Sinica. 14: $5170-5177$.

5. Clarke B. (2010) Briefing: Carbon critical design. J. Engineering Sustainability.163 (2): 57-59.

6. $\mathrm{Xu} \mathrm{W.} \mathrm{(2012)} \mathrm{Low-Carbon} \mathrm{Housing} \mathrm{and}$ Community Application Technology Guidelines. China Construction Industry Press, Beijing.

7. Lehmann S. (2014) The Principles of Green Urbanism: Transforming the City for Sustainability. Electronic Industry Press, Beijing.

8. Hachem C. (2016) Impact of neighborhood design on energy performance and GHG emissions. J. Applied Energy. 177: 422-434.

9. Lehmann S. (2015) Low Carbon Cities: Transforming Urban Systems. Routledge, Abingdon and New York.

10. Qin B., Han S. (2013) Planning parameters and household carbon emission: Evidence from highand low-carbon neighborhoods in Beijing. J. Habitat International. 37: 52-60.

11. Lin J., Ye Z.(2019) Green Urban Renewal: An Important Direction for Urban Development in the New Era. J. City Planning Review. (11): 9-12.

12. ARUP. (2010) Conceptual planning of Beijing Changxindian low-carbon community. J. Urbanism and Architecture. 2: 44-46.
13. Zhu L., Goethert R. (2009) Upgrading historic cities by integrated and innovative solutions. J. Municipal Engineering. 162(2): 87-94. 